DOE/RL-96-43

Rev. 0

\title{
Sampling and Analysis Plan for the 100-D Ponds Voluntary Remediation Project
}




\section{DISCLAIMER}

This report was prepared as an account of work sponsored by an agency of the United States Government. Neither the United States Government nor any agency thereof, nor any of their employees, makes any warranty, express or implied, or assumes any legal liability or responsibility for the accuracy, completeness, or usefulness of any information, apparatus, product, or process disclosed, or represents that its use would not infringe privately owned rights. Reference herein to any specific commercial product, process, or service by trade name, trademark, manufacturer, or otherwise does not necessarily constitute or imply its endorsement, recommendation, or favoring by the United States Government or any agency thereof. The views and opinions of authors expressed herein do not necessarily state or refiect those of the United States Government or any agency thereof. 


\section{DISCLAIMER}

Portions of this document may be illegible electronic image products. Images are produced from the best available original document. 


\section{CONTENTS}

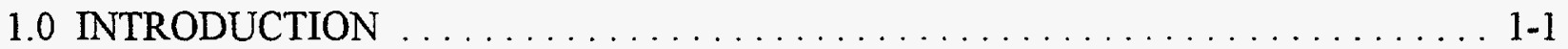

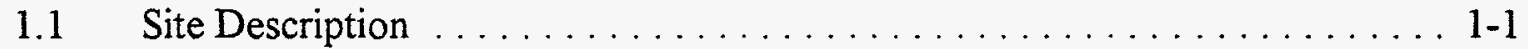

1.2 Project Description ............................. 1-2

1.3 Characterization Sampling $\ldots \ldots \ldots \ldots \ldots \ldots \ldots \ldots \ldots \ldots \ldots \ldots \ldots \ldots \ldots$

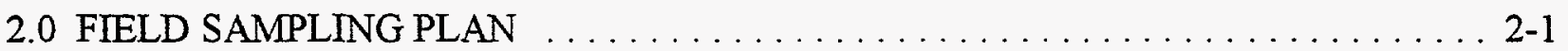

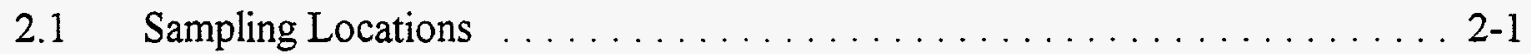

2.2 Sample Collection .............................. 2-4

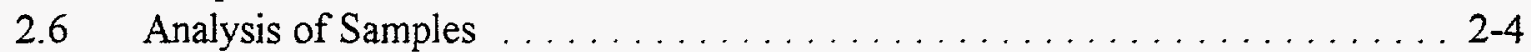

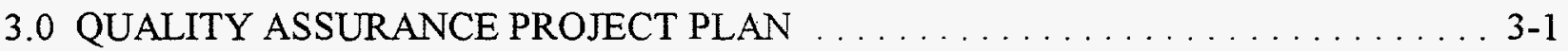

$3.1 \quad$ Project Description . . . . . . . . . . . . . . . . . . . . . . 3-1

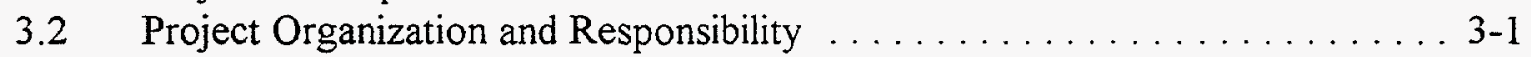

3.3 Quality Assurance Objectives for Sampling and Measurements .......... 3-1

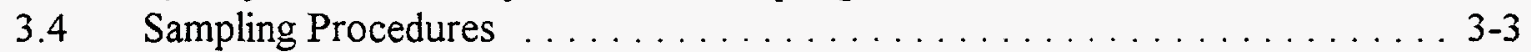

3.5 Sample and Record Custody . . . . . . . . . . . . . . . . . . . . . 3-4

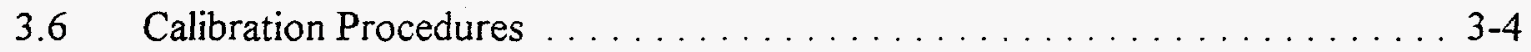

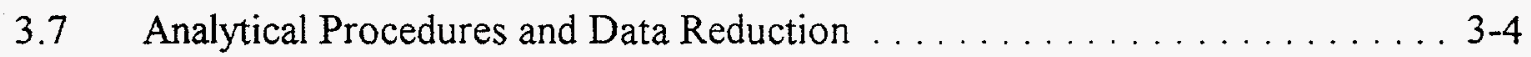

3.8 Data Reporting and Validation . . . . . . . . . . . . . . . . . . 3-5

3.9 Internal Quality Control . . . . . . . . . . . . . . . . . . . . 3-6

3.10 Performance and System Audits . . . . . . . . . . . . . . . . . . 3-7

3.11 Preventative Maintenance ... . . . . . . . . . . . . . . . . . . . . 3-8

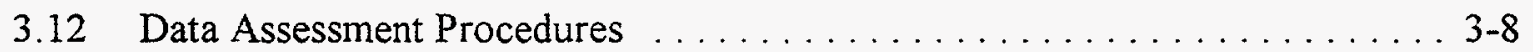

3.13 Corrective Action . . . . . . . . . . . . . . . . . . . . . . . 3-8

3.14 Quality Assurance Reports . . . . . . . . . . . . . . . . . . . 3-8

4.0 REFERENCES . . . . . . . . . . . . . . . . . . . . . . . . . . . . 4-1

FIGURES

1. Map Showing Location of 100-D Ponds . . . . . . . . . . . . . . . . 1-4

2. Topographic Map Showing Sampling Localities in 100-D Ponds $\ldots \ldots \ldots \ldots \ldots .2-3$

\section{TABLES}

1. Field Coordinates for Sampling Locations, Measured from Center of Discharge Pipe . . . . 2-2

2. Contaminants of Concern, Cleanup Limits, and Detection Limits for 100-D Ponds . . . . . 2-6 


\section{ACRONYMS}

$\begin{array}{ll}\text { COC } & \text { contaminants of concern } \\ \text { DQO } & \text { data quality objectives } \\ \text { FSP } & \text { field sampling plan } \\ \text { FSR } & \text { field sample requirements } \\ \text { HEIS } & \text { Hanford Environmental Information System } \\ \text { PCB } & \text { polychlorinated biphenyls } \\ \text { RCRA } & \text { Resource Conservation and Recovery Act } \\ \text { QA } & \text { quality assurance } \\ \text { QAPjP } & \text { quality assurance project plan } \\ \text { QC } & \text { quality control } \\ \text { SAP } & \text { sampling and analysis plan } \\ \text { TSD } & \text { treatment, storage, and/or disposal } \\ \text { VOA } & \text { volatile organics analysis }\end{array}$




\subsection{INTRODUCTION}

This Sampling and Analysis Plan (SAP) describes the sampling and analytical activities which will be performed to support closure of the 100-D Ponds Resource Conservation and Recovery Act (RCRA) treatment, storage, and/or disposal (TSD) unit. This SAP includes the Field Sampling Plan (FSP) presented in Section 2.0, and the Quality Assurance Project Plan (QAPjP) described in Section 3.0. The FSP defines the sampling and analytical methodologies to be performed, and the QAPJP provides or includes information on the requirements for precision, accuracy, representativeness, comparability, and completeness of the analytical data.

This sampling and analysis plan was developed using the Environmental Protection Agency's Seven-Step Data Quality Objectives (DQO) Guidance (EPA, 1994). The purpose of the DQO meetings was (1) to identify the contaminants of concern and their cleanup levels under the Washington State Model Toxics Control Act (MTCA, WAC-173-340) Method B, and (2) to determine the number and locations of samples necessary to verify that the 100-D Ponds meet the cleanup criteria. The data collected will be used to support RCRA closure of this TSD unit.

The DQO participants included the Washington State Department of Ecology (Ecology) unit manager and Ecology regulatory, chemistry, and hydrogeology support, the DOE-RL project manager, the ERC task lead, an ERC DQO facilitator, ERC regulatory support, and ERC environmental sciences and engineering personnel. The team utilized ERC's DQO process template to identify and resolve key project issues related to the purpose of the study, use of historical data to plan the current study, sample collection (location, volume, and frequency), analytes of interest, analytical methods, data quality needs, data use and interpretation, and the uncertainties associated with the study (BHI 1996a). This sampling and analysis plan represents a resource-effective study design that was mutually agreed to by the project team and satisfies the DQO requirements for sampling of 100-D Ponds.

\subsection{Site Description}

The 100-D Ponds is an interim status RCRA TSD unlined surface impoundment (disposal ponds), located north of the perimeter fence of the 100-D Area (Figure 1-1). The TSD unit consists of two ponds: a percolation pond to the north and a settling pond to the south. The two ponds were excavated into previously existing coal ash (126-D-1 Ash Disposal Basin, a Comprehensive Environmental Response, Compensation, and Liability Act unit). The source of this coal ash was the 184-D Powerhouse, which was in operation from 1950 to 1966 . The ash was deposited into an excavated basin as a slurry that had been discharged through the 100-D Area industrial sewer system.

This TSD unit was constructed as one pond in 1977 to receive liquid effluent from the 100-D industrial sewer system. To eliminate a bottom sealing problem, the original pond was divided into two ponds in 1979. The ponds are separated by an earthen dike and connected by metal pipes so that water from the settling pond could be diverted to the percolation pond. According to records, very little water was spilled into the percolation pond. 
The effluent discharged into the ponds originated mainly from the 183-D Water Treatment Facility. This effluent consisted of alum-precipitated sand filter backflush and wash water from the settling basins. The other principle source of effluent came from the 189-D Mechanical Development Laboratory, which contributed corrosive demineralizer regenerative solutions to the waste stream and potentially discharged miscellaneous undocumented chemicals through the process sewer system. The 100-D Ponds have not received dangerous waste since 1986, and discharges were completely suspended in June, 1994.

Solid and colloidal materials suspended in the discharged effluent contributed to the 60 to $150 \mathrm{~cm}$ ( 2 to $5 \mathrm{ft}$ ) thick layer of sediment which currently occupies the bottom of the settling pond. This layer contains elevated concentrations of several heavy metals and polychlorinated biphenyls (PCB); however, characterization data indicates that the contamination does not continue into the ash underlying the pond.

\subsection{Project Description}

The 100-D Ponds is undergoing RCRA Closure. A closure plan was submitted (DOE/RL 1992), and will be revised by September 1997 to meet the Hanford Site Permit modification scheduled for 1998. The revision will incorporate comments from reviews by Ecology and subsequent responses from $\mathrm{DOE} / \mathrm{RL}$.

Sediments from the 100-D Ponds are being removed to support the closure. Most or all of the material removed will be from the southern (settling) pond. Because this material contrasts in color and texture from the underlying coal ash, identifying the thickness of sediment to be removed and disposed of will be made in the field during excavation. Near-surface verification samples will be collected after sediment removal, and analytical results will be included in the closure plan.

Overall objectives of this project follow:

1. Follow all applicable DOE, RL, ERC, state, and federal requirements during all phases of the work including achieving ERC's "zero accident" policy.

2. Achieve remediation standards. Remediation will be considered complete when all contaminants of concern have been reduced to cleanup goals as presented in Table $2-2$.

3. Use visual observation to delineate the ash/sediment boundary for guiding excavation. Existing data on thickness of ash will be used to guide excavation.

4. Use results of laboratory analyses to verify that remediation goals have been met. 


\subsection{Characterization Sampling}

There have been two sampling and analysis efforts for characterization of 100-D Ponds. Phase I sampling was performed in August and September 1992 and was designed to provide information to develop a closure strategy for the ponds. Only surface samples were collected during Phase I sampling (WHC 1992).

Phase II sampling was performed in January 1995. As part of that effort, test pits up to 2.4 meters ( 8 feet) deep were excavated to collect soil samples for volatile organics analysis (VOAs), semi-VOAs, PCBs, metals, anions, total organic halides, and radiological constituents. Split samples were also collected and analyzed by Ecology. This field activity is described in Description of Work for 100-D Ponds Sampling, Phase II (BHI 1995a). The analytical results are reported in Data Evaluation: 100-D Ponds (BHI 1995b). Results from this sampling and analysis effort guided selection of the contaminants of concern. These results also indicated that the sediments at the bottom of the settling pond were the only materials associated with the TSD that contained analyte concentrations above cleanup limits.

The Phase II data were collected for characterization purposes and to determine if a barrier around the ponds was required. Consequently, those data have been determined to be unsuitable for purposes of verification for clean closure of this RCRA TSD unit (BHI 1996a). The samples to be collected and analyzed in the effort described here will be used to verify that near-surface soils from 100-D Ponds are below cleanup levels. 
Figure 1-1. Map Showing Location of 100-D Ponds.

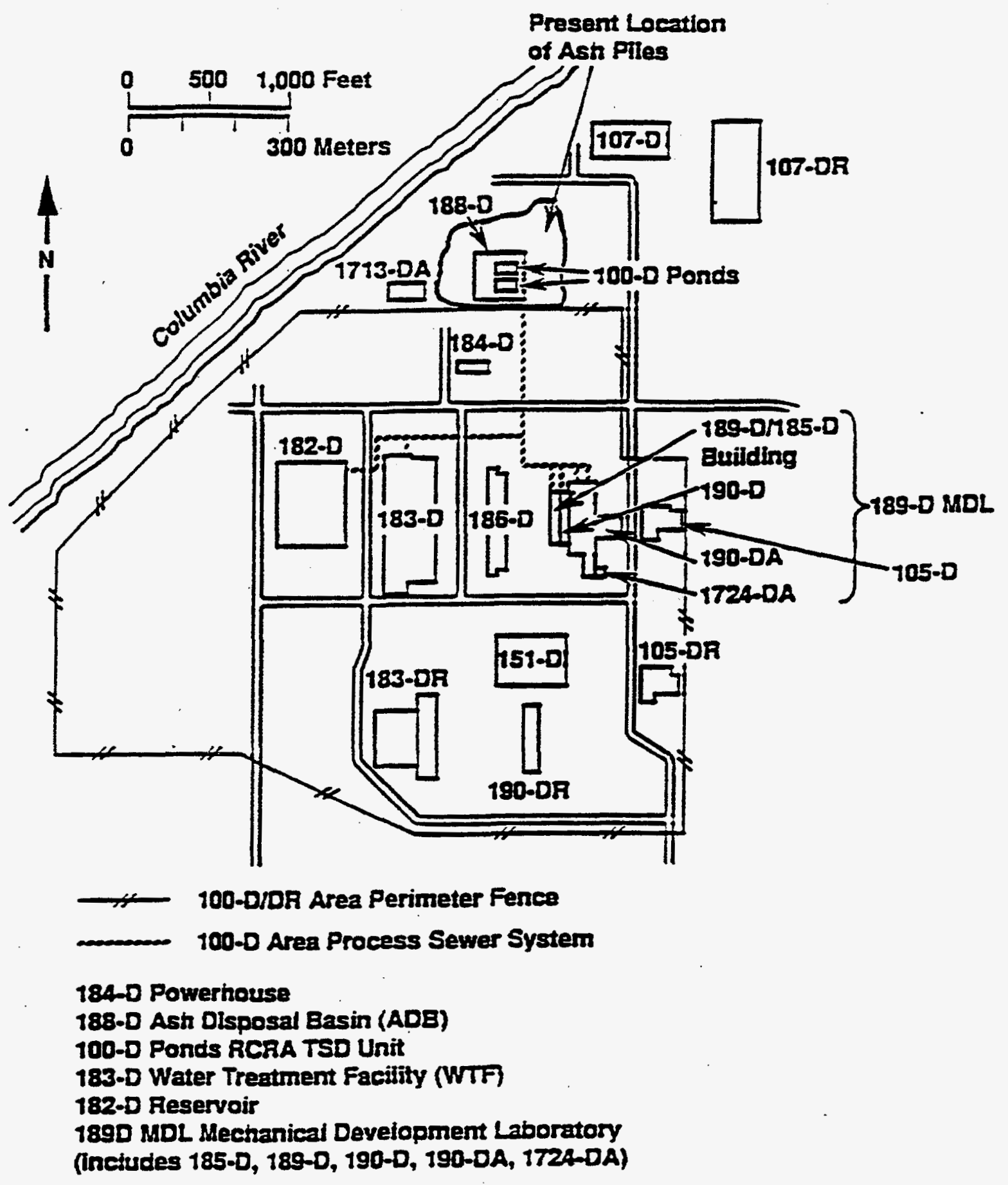




\subsection{FIELD SAMPLING PLAN}

This FSP defines the methodologies that will be used during near-surface verification sampling of 100-D Ponds. It includes, either specifically or by reference, the method of sample collection, the location of samples, the contaminants of concern, and the analytical methods and detection limits.

\subsection{Sampling Locations}

Sampling locations were determined during the DQO process and reported in the DQO Summary Report (BHI 1996a). A combination of random and judgement samples will be collected, guided in part by the results of the previous Phase I and Phase II sampling and analysis efforts (BHI 1995b). Locations of verifications samples to be collected for this sampling activity are identified in Figure 2-1. Coordinates for the sampling sites, measured from the center of the discharge pipe in the northeast corner of the settling pond, are presented in Table 2-1.

\subsubsection{Settling Pond Verification Samples}

A total of 9 verification samples will be collected from the bottom of the settling pond. Six judgement samples will be collected from the following locations that were sampled during the Phase II effort conducted in January 1995 (BHI 1995b):

- $\quad$ Test Pits 1 and 2 (Samples TP1 \& TP2, Figure 2-1)

- $\quad$ Surface Samples 1, 5, 6, and 7 (Samples S1, S5, S6, and S7, Figure 2-1)

Three random samples will be collected from the middle of the pond to supplement areal coverage of the pond. These samples were chosen by constructing a 7-by-5 grid with lines spaced 3 meters (3.3 yds) apart, in the middle third of the settling pond. A random number generator was used to select 3 of the nodes in the grid. The location of these samples is marked on Figure $2-1$, and the samples are designated SR1 through SR3.

\subsubsection{Percolation Pond Verification Samples}

Five random samples will be collected from the Percolation Pond. Locations were chosen by overlaying the pond with a 9-by-6 grid, with lines spaced 3 meters apart. A random number generator was then used to select 5 nodes in the grid. Sample locations are shown in Figure 2-1, and identified as Pl through P5.

\subsubsection{Banks of the Ponds}

The lower third of the banks of each pond will be sampled at a frequency of 1 sample for every $100 \mathrm{~m}^{2}\left(120 \mathrm{yd}^{2}\right)$ of surface area (BHI 1996a). Assuming a total bank height of $6 \mathrm{~m}(6.6 \mathrm{yd})$ and circumference of $42 \mathrm{~m}$ ( $46 \mathrm{yd}$ ), approximate sampling area of the percolation pond is $85 \mathrm{~m}^{2}$ (100 $\left.\mathrm{yd}^{2}\right)$. The bank height and circumference of the settling pond will not be known until excavation of the sediments is complete. Therefore, the total area to be sampled is unknown at this time but 
will likely be between $100 \mathrm{~m}^{2}\left(120 \mathrm{yd}^{2}\right)$ and $200 \mathrm{~m}^{2}\left(240 \mathrm{yd}^{2}\right)$. Thus, 1 sample will be collected from the banks of the percolation pond; if bank area of the settling pond is between 100 and 200 $\mathrm{m}^{2}$, two samples will be collected.

Specific locations of the bank samples will be determined by measuring the circumference of the bank and choosing a random number (or two, if total area is greater than $100 \mathrm{~m}^{2}$ ) between 0 and the circumference. The sample will be located at the distance corresponding to the number chosen. An exception to this will be the bank sample(s) from the settling pond, where judgement sample S1 (Figure 2-1) will be used as a bank sample and will be the origin of the circumferential measurement of the bank. Sample S1 was chosen as a judgement sample because Phase II analytical data indicated elevated levels of some metals in this location. The second sample (if needed) will be chosen randomly.

Table 2-1. Field Coordinates for Sampling Locations, Measured from Center of Discharge Pipe.

\begin{tabular}{|c|c|c|}
\hline Settling Pond Sample \# & West of Discharge Pipe (m) & South of Discharge Pipe (m) \\
\hline S1 & 5.0 & 13.6 \\
\hline S5 & 36.0 & 3.8 \\
\hline S6 & 14.8 & 17.3 \\
\hline S7 & 2.3 & 0.5 \\
\hline TP1 & 36.3 & 15.3 \\
\hline TP2 & 6.9 & 1.6 \\
\hline SR1 & 26.5 & 4.3 \\
\hline SR2 & 20.4 & 4.3 \\
\hline SR3 & 29.5 & 13.0 \\
\hline Percolation Pond Sample \# & West of Discharge Pipe & North of Discharge Pipe \\
\hline P1 & 13.8 & 29.5 \\
\hline P2 & 19.3 & 27.1 \\
\hline P3 & 16.3 & 20.5 \\
\hline P4 & 25.4 & 20.5 \\
\hline P5 & 29.1 & 20.5 \\
\hline
\end{tabular}


DOE/RL-96-43

Rev. 0

Figure 2-1. Topographic Map Showing Sampling Localities in 100-D Ponds.

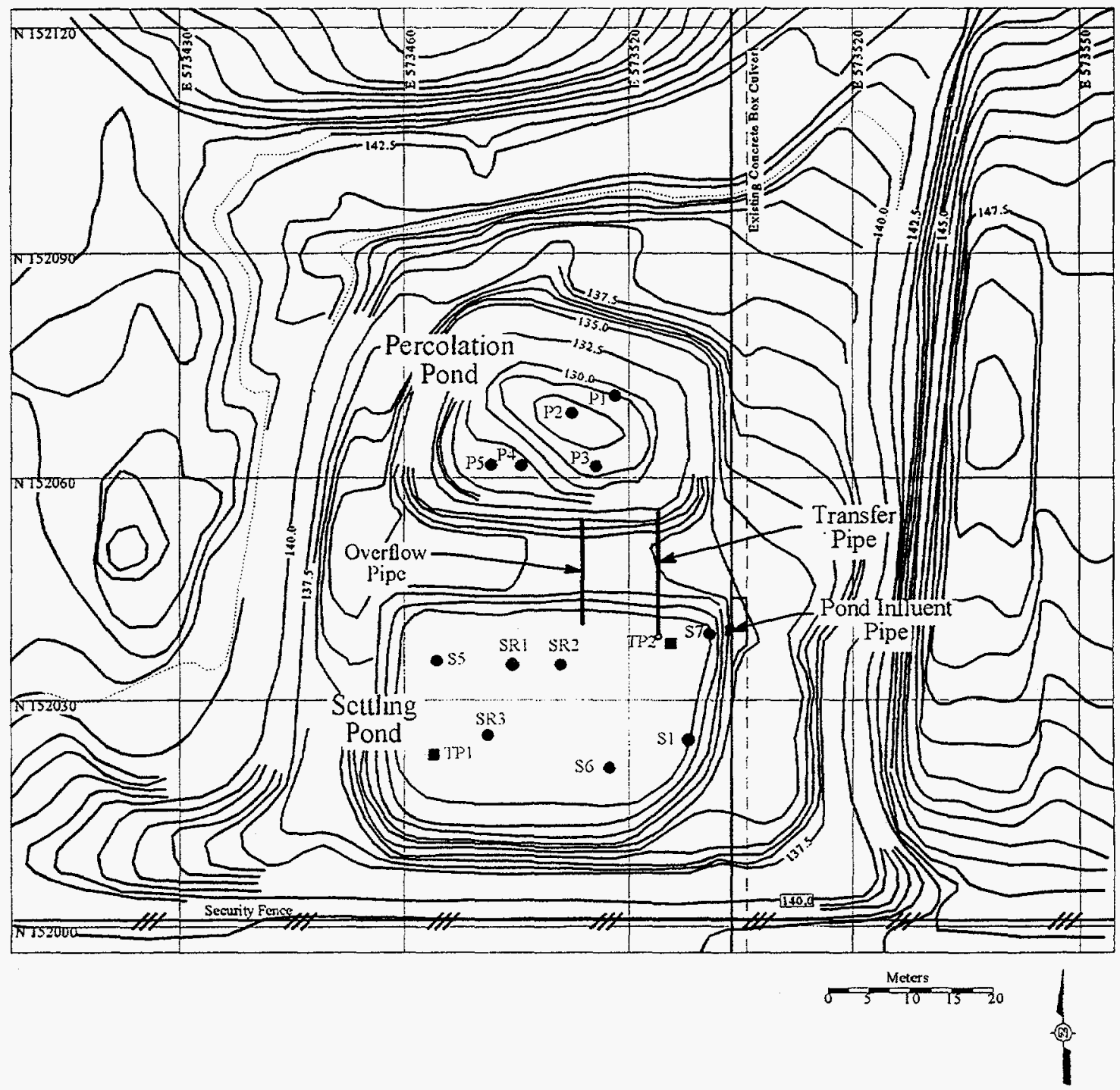




\subsection{Sample Collection}

As discussed in the DQO workshop, samples will be collected 30 to $60 \mathrm{~cm}$ (1 to $2 \mathrm{ft}$ ) below remediation grade. Details regarding the quality assurance/quality control aspects of sampling and analysis (e.g., field duplicates, sampling procedures) are discussed in Section 3.

\subsection{Analysis of Samples}

A list of the contaminants of concern (COC) as determined during the DQO process is presented in Table 2-2 along with the target detection limits. The COCs are comprised of selected metals and PCBs. Sample analysis methods, preservation, hold times, and volume requirements will be identified through the process defined by BHI-EE-01, Procedure 2.0, "Sample Event Coordination" and documented on the Sample Authorization Form/Field Sample Requirements form prepared by sample management. Specific analytical methods are identified in Section 3.7. 
Table 2-2. Contaminants of Concern, Cleanup Levels, and Method Detection Limits for 100-D Ponds.

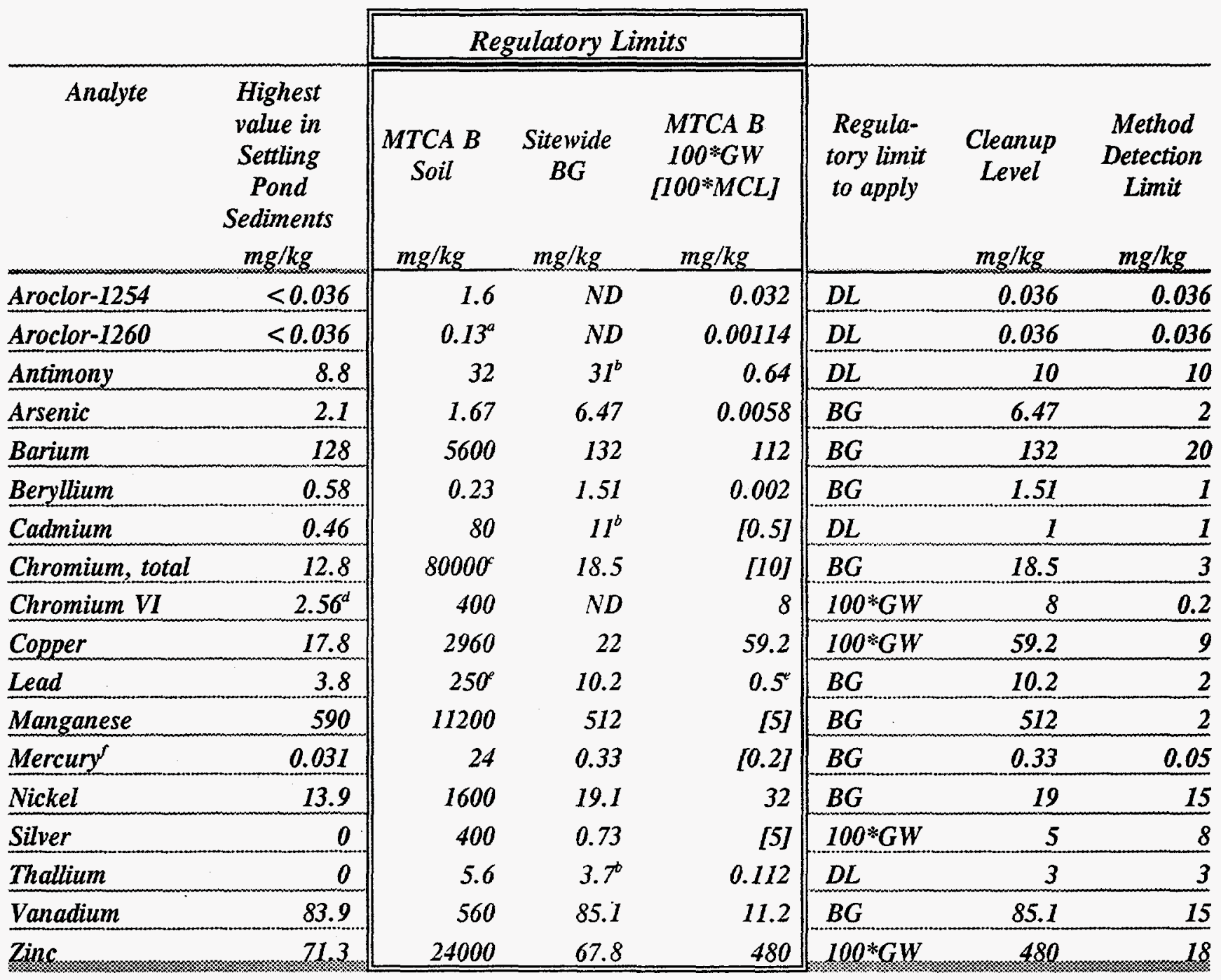

a MTCA B value applied to Aroclor-1260 is for total PCBs.

b Highest background value; 90 th percentile not calculated owing to paucity of data

c MTCA values are for chromium III; cleanup values for total chromium are not tabulated.

d Value is extrapolation of TCLP analyses on SP-7, a Phase 1 surface sample from the seuling pond

e MTCA Method A values used for lead, as required by Ecology

f Only 1 sample below 2' was analyzed, in an Ecology split sample

MTCA B $=$ MTCA $B$ soil value

$B G=$ background

$\mathrm{DL}=$ detection limit

ND $=$ not determined

$100 * G W=100$ times MTCA B groundwater value

100* $\mathrm{MCL}=100$ times EPA's Maximum Contaninant Level (value for manganese is the secondary $\mathrm{MCL}$ )

Sitewide BG = Lognormal 90th percentile of the Sitewide background data set 
DOE/RL-96-43

Rev. 0 
DOE/RL-96-43

Rev. 0

\subsection{QUALITY ASSURANCE PROJECT PLAN}

\subsection{Project Description}

This QAPJP covers the sampling and analysis of the 100-D Ponds RCRA TSD unit. A description of this unit is provided in Section 1.2.

\subsection{Project Organization and Responsibility}

The general project organization and individual responsibilities are identified in "Work Plan for the Excavation of Contaminated Materials from I00-D Ponds" (BHI 1996b). Detailed responsibilities of the sampling team are outlined in the referenced procedures in BHI-EE-01 "Environmental Investigative Procedures."

\subsection{Quality Assurance Objectives for Sampling and Measurements}

To address the workscope outlined in the project plan, the quality assurance (QA) objectives established for this project are provided in the following list. The methods and procedures used to implement and accomplish the following objectives are described throughout the plan.

- Implement standard operating procedures for field sampling, sample custody, equipment operation and calibration, laboratory sample analysis, data reduction, and data reporting that will ensure the consistency and thoroughness in data generated.

- $\quad$ Assess the quality of data generated to ensure that all data are scientifically valid, are of known and documented quality, and are legally defensible. This is largely accomplished by establishing DQOs for parameters such as precision, accuracy, completeness, representativeness, and comparability, and by testing generated data against accepted criteria established for these parameters.

- Achieve an acceptable level of confidence in the decisions that are made from data by controlling the degree of total error permitted in the data by using quality control (QC) checks. Data that fail the QC checks, or do not fall within acceptance criteria established, will be rejected from further use or qualified for limited use.

- $\quad$ Ensure that the QAPjP and associated project plans are properly implemented by conducting compliance inspections and audits. In addition, verify by reinspection that corrective action is implemented and maintained for any nonconformance identified and provide QA reports to management and Ecology. 


\subsubsection{Data Quality Objectives}

Parameters have been established for each of the five data assessment areas identified in the following sections. These objectives are expressed as qualitative statements concerning the type of data needed to support a decision.

3.3.1.1 Precision. Precision is the measure of mutual agreement among replicate (or between duplicate) or co-located sample measurements of the same analyte. The closer the number values of the measurements are to each other, the more precise the measurement. Precision for a single analyte will be expressed as a percentage of the difference between results of replicate samples or matrix spike duplicates. The precision goal for this project is $\pm 20 \%$ for all analyses.

3.3.1.2 Accuracy. Accuracy is a measure of bias in a measurement system. The closer the value of the measurement agrees with the true value, the more accurate the measurement. This will be expressed as the percent recovery of a known spike analyte or a standard reference sample. For all analyses, the accuracy goal is $80 \%$ to $120 \%$ recovery.

3.3.1.3 Completeness. Completeness measures the amount of valid data obtained from a measurement system compared to the amount that was expected to be obtained under normal conditions.

$$
\% \mathrm{C}=100 \times \mathrm{V} / \mathrm{n}
$$

where:

$\mathrm{V}=$ Number of valid data points acquired

$\mathrm{n}=$ Total number of data points

The goal for completeness in this project is set at $100 \%$ of validated data. If this cannot be achieved due to inadequate $\mathrm{QC}$ by the laboratory, the laboratory may be requested to reanalyze the sample. If samples are compromised, resampling may be required.

3.3.1.4 Representativeness. Representativeness will be achieved by using BHI-approved sampling procedures or EPA-approved analytical methods.

3.3.1.5 Comparability. Comparability expresses the confidence with which one data set can be compared to another data set given similar precision, accuracy, detection limit, analytical method, and sample matrix. Comparability for this project will be ensured by the use of SW-846 methods for analysis and achievement of the required method detection limits. 


\subsection{Sampling Procedures}

All sampling will be performed in accordance with procedures identified in BHI-EE-01. Sample packaging and shipping will be performed in compliance with BHI-EE-01, Procedure 3.1. Custody seals will be applied to all sample containers. Logbook entries will be performed in compliance with BHI-EE-01, Procedure 1.5. Copies of the logbook will be made available to Ecology. Custody will be maintained in accordance with BHI-EE-01, Procedure 3.0.

\subsubsection{Quality Assurance/Quality Control Sampling Requirements}

Quality control samples to be collected include field duplicates, field blanks, and field splits. Field duplicates will be collected at a frequency of one per 10 soil samples collected or one per day, whichever is greater. Field blanks will be collected at a frequency of one per 20 soil samples.

The field duplicates will be used to help evaluate spatial variability resulting from sample heterogeneity. A field duplicate is an unique sample taken from a co-located position near the routine sample. The location of the duplicates will be chosen randomly in the field by the samplers.

Field blanks are used to assess environmental and sampling equipment contamination. An undetermined number of split samples will be collected by Ecology and analyzed in a separate laboratory.

\subsubsection{Sample Designations}

Each sample collected will receive an unique Hanford Environmental Information System (HEIS) identification number in accordance with BHI-EE-01, Procedure 2.0 "Sample Event Coordination." The field sampler will identify the locations from which the samples were collected (identified in Section 2.1), and record the samples in the field logbook (BHI-EE-01, Procedure 1.5), along with their respective HEIS number. The samplers will identify each location with a stake labeled with the corresponding HEIS number(s). Sampling locations will then be surveyed per BHI-EE-01, Procedure 1.6, and BHI-EE-09, Procedure 1.8

\subsubsection{Sampling Procedures}

Samples described in this plan will be collected in accordance with BHI-EE-01, Procedure 4.0 "Soil and Sediment Sampling." As discussed in the DQO workshop, samples will be collected 30 to $60 \mathrm{~cm}$ ( 1 to $2 \mathrm{ft}$ ) below remediation grade. Any sampling equipment (e.g., spoons, bowls, trowels, etc.) that is to come in contact with the soil must be precleaned in accordance with WHCCM-7-7, EII 5.5. If available, disposable precleaned plastic equipment may be used in lieu of cleaned stainless steel.

All sampling will be conducted in compliance with the site safety plan. 


\subsubsection{Sample Handling}

Collection and handling of samples shall comply with procedures identified in BHI-EE-01. Samples removed from the immediate sampling site for analysis shall be controlled as required by BHI-EE-01, Procedure 3.0, "Chain of Custody." Custody seals will be affixed in the field to each sample container, prior to shipping the samples.

Sample packaging and shipping will be performed in compliance with BHI-EE-01, Procedure 3.1, "Sample Packaging and Shipping." Logbook entries will be performed in compliance with BHIEE-01, Procedure 1.5, "Field Logbooks."

\subsection{Sample and Record Custody}

\subsubsection{Field Custody}

All samples obtained during the course of this project will be controlled from the point of origin to the analytical laboratory as required by BHI-EE-01, Procedure 3.0. Custody seals will be applied in the field prior to transport of samples

\subsubsection{Laboratory Custody Procedures}

Sample custody during laboratory analysis will be addressed in the applicable laboratory standard operating procedures. Laboratory custody procedures will ensure the maintenance of sample integrity and identification throughout the analytical process.

\subsubsection{Final Custody Procedures}

All relevant documents, records, reports, logs, field notebooks, pictures, subcontract reports, and analytical reports will be submitted, secured, and stored in accordance with BHI-MA-02, Procedure 1.7, "ERC Records Management."

\subsection{Calibration Procedures}

All sampling and analytical equipment used in association with this activity will be calibrated to operate within the specifications provided by the manufacturer. Calibrations will be performed as stipulated by the manufacturer's calibration procedure, the project-specific calibration procedure, or an analytical method.

\subsection{Analytical Procedures and Data Reduction}

Analytical methods to be used by the laboratories will be specified by completing a request for analytical services (form number BHI-EE-003), and in accordance with BHI-EE-01, Procedure 2.0, the project work order, or the contractor procurement document. 
Samples will be processed following EPA SW-846 Methods. Most metals will be analyzed according to EPA SW-846 Method 6010A, titled Inductively Coupled Plasma-Atomic Emission Spectroscopy. Arsenic will be analyzed by EPA method 7060 , lead by method 7421 , thallium by EPA method 7841, mercury by EPA method 7471, and hexavalent chromium by EPA method 3060A. Analysis of PCBs will conform to EPA protocols (e.g., SW-846 Method 8080A, Organochlorine Pesticides and PCBs by Gas Chromatography). Holding times and volume requirements will meet the requirements of EPA SW-846 methods, as listed in Table 1 of Chapter 3.

Data-reduction schemes will be contained within laboratory analytical methods or laboratory procedures. The requirements of this section will be included in procurement documentation or work orders, as appropriate.

\subsection{Data Reporting and Validation}

\subsubsection{Reporting}

All data generators must prepare a report summarizing the results of analysis. Data summaries shall include, at a minimum, sample identity, sampling and analysis dates, and reduced data results. All data necessary to perform sample validation will also be reported. These data will include, but are not limited to, the following: sample number, sampling and analysis dates, reduced data, data outliers, recovery percentages, QC check data, and documentation of any nonconformance affecting the measurement system.

The completed data package will be reviewed and approved by the analytical laboratory's QA manager (or delegate). Completed reports/data packages will be submitted to Sample Management. Copies of the data will be made available to Ecology. The requirements of this section will be included in procurement documentation or work orders, as appropriate. The data packages will be verified by ERC or their subcontractor following the steps detailed in BHI-EE-01, Procedure 2.4

\subsubsection{Validation}

Validation of completed data packages will be performed by a qualified subcontractor. Data validation will be in accordance with WHC-SD-EN-SP-002, "Data Validation Procedures for Chemical Analyses." Validation will be made to level D.

All coordination of validation services, execution of data validation activities, and handling and storage of deliverables will be accomplished in accordance with BHI-EE-01, Procedure 2.5. One sample delivery group consisting of approximately 20 samples will be $100 \%$ validated to existing procedures. It is anticipated that all samples collected in conjunction with this SAP will be submitted in one sample delivery group. 
3.8.2.1 Data Management. Data generated as a result of laboratory analysis will be managed, validated, and stored by the sample management group, as outlined in BHI-EE-01 Procedure 2.0 "Sample Management."

Project data access will be provided to DOE and the regulators. Electronic data access, when appropriate, will be through computerized data bases (such as HEIS). Where electronic access to data is not available, hard copies of laboratory data will be provided in accordance with Section 9.6 of the Tri-Party Agreement.

\subsubsection{Final Review and Records Management Considerations}

At the direction of the analytical support technical lead, before being submitted to regulatory agencies or included in reports or technical memoranda, all validated reports and supporting analytical data packages will be subject to final technical and QC review by qualified reviewers. All validation reports and data packages will be retained as permanent project records in compliance with the Document Control section of BHI-MA-02.

\subsection{Internal Quality Control}

Several control samples are introduced into the collection and analytical system to monitor the adequacy of the sampling system and the integrity of samples during their journey from the field collection point through laboratory analysis. The types of QC samples to be collected have been discussed in Section 2.2 and are defined, along with their mode of collection and purpose, in the following sections.

\subsubsection{Field Quality Control}

3.9.1.1 Field Duplicates. Field duplicates are two unique, co-located samples, handled independently. Each sample will be numbered uniquely. Field duplicates are sent to the same laboratory in the same manner as routine samples, but will not be identified to the laboratory as field duplicates. Field duplicate data will be evaluated for precision; the data for constituents that are not contaminants are expected to be within $20 \%$ RSD.

3.9.1.2 Field Splits. Field splits are two samples produced from material collected in the same location and mechanically homogenized. Each sample is given a unique number and the two samples are sent to different laboratories. Split samples are sent to the specified laboratories in the same manner as routine samples.

3.9.1.3 Field Blanks. Field blanks are prepared by transferring clean silica sand into a sample container at the site. Field blanks are used as a check of environmental contamination. 


\subsubsection{Analytical Laboratory Quality Control}

The laboratory quality control samples required to meet EPA criteria are identified in the specific laboratory methods described in Section 2.6. Definitions of these sample types are found below.

3.9.2.1 Matrix Spike Samples/Matrix Spike Duplicate Samples. Matrix spike samples require the addition of a known quantity of a representative analyte of interest to the sample as a measure of recovery percentage. The spike shall be made to a test portion of a routine sample. Replicate samples are separate aliquots removed from the same sample container in the laboratory. Spike compound selection, quantities, and concentrations are described in the analytical procedures. Matrix spike duplicates consist of a second matrix spike sample made from the same field sample as the matrix spike sample.

3.9.2.2 Replicate Samples. Replicate samples are separate aliquots removed from the same sample container in the laboratory. They are equivalent to test portions.

3.9.2.3 Quality Control Reference Samples. The QC reference samples will be prepared from an independent standard, wherever possible, at a concentration other than that used for calibration but within the calibration range. Reference samples are required as an independent check on analytical technique and methodology.

3.9.2.4 Analytical Blanks. Analytical blanks are materials known to be free from contamination that are carried through the same preparation and analytical procedures as the sample, using the same reagents. They are used to evaluate potential laboratory contamination of samples. A minimum of one analytical blank will be prepared and analyzed for each sample delivery group.

\subsection{Performance and System Audits}

The BHI QA Department may conduct random and periodic surveillance and assessments to verify compliance with the requirements outlined in this QAPjP, the project work packages, the BHI Quality Management Plan, and BHI procedures and regulatory requirements. Collectively, the surveillance and assessments will address quality-affecting activities that include, but are not limited to, measurement system accuracy, field activities, data collection, processing, validation, management, and QA programs. Personnel performing the surveillance have the authority to stop work when such work is in violation of the QA program or the Health and Safety program, as outlined under BHI-QA-02.

System audits consist of the evaluation of the components of the measurement systems to determine their proper selection and use. Performance audits ensure the accuracy of the total system and its individual parts. Random surveillance and assessments will be structured to meet the following system and performance audit classification. 


\subsection{Preventative Maintenance}

All measurement and testing equipment used in the laboratory that directly affects the quality of the analytical data are subject to preventative maintenance measures that ensure minimization of measurement system downtime. Laboratories must maintain their equipment. Maintenance requirements, such as parts lists and instructions, are included in the individual laboratory QA plan or operating procedures.

\subsection{Data Assessment Procedures}

Analytical data will be compiled and reduced by the laboratory and validated in a manner appropriate for the individual analytical method (Section 3.8.2). Following this, various statistical and probabilistic techniques will be selected and employed for comparison and analysis of the data, as directed by the technical lead. These techniques will include the 3-part comparison test described in WAC-173-303-740(7)(e) for each analyte that has a cleanup limit equal to MTCA B levels (Table 2-2). For those analytes with background as the cleanup limit, nonparametric hypothesis tests will be used to compare all of the data from 100-D Ponds to the range of background compositions for that analyte (DOE/RL 1994).

The statistical methodology and the assumptions to be made will be defined by written directions that are signed and dated and retained as project records.

\subsection{Corrective Action}

Corrective action required as a result of surveillance reports, nonconformance reports, or audit activities will be documented and dispositioned, as required by BHI-MA-02, Section 2.1, Corrective Action. Other measurement systems, procedures, or plan corrections that may be required, as a result of routine review processes, will be resolved as required by governing procedures or will be referred to the technical lead for resolution. Ecology will be notified of the need for any corrective action and the corrective action taken.

\subsection{Quality Assurance Reports}

All findings from audits, surveillance, and assessments will be transmitted to the project manager and the BHI QA department for program-related tracking and trending. Otherwise, the routine evaluation of data quality described throughout this QAPjP will be documented and filed along with the data in the project file. The final report will include an evaluation of the overall adequacy of the total measurement system with regard to the DQO of the data generated. 


\subsection{REFERENCES}

BHI, 1995a, Description of Work for 100-D Ponds Sampling, Phase II, BHI-00140, Rev. 01, Bechtel Hanford, Inc., Richland, Washington.

BHI, 1995b, Data Evaluation: 100-D Ponds, BHI-00328, Bechtel Hanford, Inc., Richland, Washington.

BHI, 1996a, Data Quality Objectives Summary Report for the 100-D Ponds Voluntary Remediation Project, BHI-00773, Bechtel Hanford, Inc., Richland, Washington.

BHI, 1996b, Work Plan for the Excavation of Contaminated Materials from 100-D Ponds, BHI-00777, Bechtel Hanford, Inc., Richland, Washington.

BHI-EE-01, Environmental Investigations Procedures, Bechtel Hanford, Inc., Richland, Washington.

BHI-QA-02, Quality Program Procedures, Bechtel Hanford, Inc., Richland, Washington.

DOE/RL, 1992, 100-D Ponds Closure Plan, DOE/RL-92-71, Rev. 1, U.S. Department of Energy, Richland, Washington.

DOE/RL, 1994, Hanford Site Background Data Applications Guide: Part 1, Soil, DOE/RL-94-72, Rev. O, U.S. Department of Energy, Richland, Washington.

EPA, 1994, Guidance for the Data Quality Objectives Process, EPA QA/G-4, U.S. Environmental Protection Agency, Washington, D.C.

WHC, 1992, Description of Work, 100-D Ponds Nonintrusive Characterization, WHC-SD-ENAP-092, Rev. 1, Westinghouse Hanford Company, Richland, Washington.

WHC, 1993, Data Validation Procedures for Chemical Analyses, WHC-SD-EN-SP-002, Rev.2, Westinghouse Hanford Company, Richland, Washington. 
DOE/RL-96-43

Rev. 0 
DOE/RL-96-43

Rev. 0

\section{DISTRIBUTION}

ON SITE (21 copies)

U.S. Department of Energy

Richland Operations Office

J. K. Erickson

A4-52

G. I. Goldberg (4)

$\mathrm{H} 0-12$

DOE/RL Public Reading Room

H2-53

ERC Team

D. L. Bryant

X5-57

C. E. Corriveau

$\mathrm{H} 0-17$

S. K. DeMers

$\mathrm{T} 7-05$

C. W. Hedel

$\mathrm{H} 0-17$

J. R. James

$\mathrm{H} 0-17$

S. W. Petersen (3)

H9-03

W. H. Price

$\mathrm{H} 0-18$

D. A. St. John

N1-28

BHI Document and Information Services (3)

H0-09

Hanford Technical Library

P8-55

Public Reading Room

$\mathrm{H} 2-53$ 
DOE/RL-96-43

Rev. 0

Dist-2 